\title{
Alginate electrodeposition onto three-dimensional porous Co-Ni films as drug delivery platforms
}

J. García-Torres*, C. Gispert, E. Gómez and E. Vallés

Ge-CPN, Physical Chemistry Department, Nanoscience and Nanotechnology Institute (IN $\left.{ }^{2} \mathrm{UB}\right)$, University of Barcelona. Martí i Franquès, 1. 08028 Barcelona (Spain)

*Corresponding author:

Phone: +34 699813563

Fax: +34934021231

e-mail: garcia.torres.jm@gmail.com 


\begin{abstract}
Three-dimensional porous $\mathrm{Co}-\mathrm{Ni}$ films/alginate hybrid materials have been successfully prepared by electrodeposition to be used as a steerable magnetic device for drug delivery. Firstly, 3D porous Co-Ni films were prepared as substrate for the subsequent eletrodeposition of the alginate biopolymer. Cyclic voltammetry, galvanostatic and potentiostatic studies were performed to establish the best conditions to obtain porous Co-Ni films. The electrochemical experiments were carried out in an electrolyte containing the metal salts and ammonium chloride at low pH's. In a second stage, the electrochemical deposition of alginate as biocompatible polymer drug delivery carrier was performed. The characteristics of the alginate matrix were investigated in terms of electrochemical properties, morphology and drug release. The hybrid material obtained showed soft-magnetic behavior and drug release indicating its suitability to be used as a steerable magnetic drug delivery device.
\end{abstract}

Keywords: electrodeposition, 3D porous Co-Ni films, alginate polymer, hemoglobin, drug delivery 


\section{Introduction}

Three dimensional nano-structured architectures have been explored for new devices such as sensors, supercapacitors, batteries, and fuel cells ${ }^{1,2}$ because of their great potential for rapid electrochemical reactions arising from the extremely large specific surface areas for charge and mass (gas) transport. Although different techniques have been employed for the preparation of these 3D networks like sol-gel chemistry, templating or de-alloying, ${ }^{3,4}$ electrodeposition has been revealed as a very effective method to fabricate them. The reason is that the hydrogen bubbles originated from the cathode reaction create a continuous path from the substrate to the electrolyte-air interface during the deposition process allowing creating this 3D porous structure. ${ }^{5,6}$

Different metallic materials and alloys have been used to successfully prepare these 3D porous materials (gold, copper, silver, copper-tin or gold-platinum, among others) mainly for electrocatalytic applications or electrode materials in batteries ${ }^{5-8}$ However, magnetic 3D porous metallic materials have never been prepared by electrodeposition with drug delivery applications. Magnetic materials have received increased attention during the last years as microrobotic systems which are wirelessly steered by a magnetic manipulation system ${ }^{9,10}$ for biomedical applications such as temporary diagnosis and treatment.

The intelligence of these devices can be defined by choosing the appropriate combination of materials and methods. In this sense, Co-Ni system has been selected for the preparation of the magnetic 3D porous materials because they show soft-magnetic properties to be wirelessly controlled and corrosion resistance to be used in body fluids. ${ }^{11,12}$ On the other hand, alginate, a naturally occurring biopolymer, is finding increasing applications in the biotechnological industry, mainly due to the unique properties to be used as a matrix for the entrapment and/or delivery of a variety of proteins, cells, drugs,... These properties include: (i) a relatively inert 
aqueous environment within the matrix; (ii) a mild room temperature encapsulation process free of organic solvents; (iii) a high gel porosity which allows for high diffusion rates of macromolecules; (iv) the ability to control this porosity with simple coating procedures and (v) dissolution and biodegradation of the system under normal physiological conditions. ${ }^{13,14}$

In this study we first report the study of the electrodeposition process of 3D porous Co-Ni films which will act as the magnetically-controlled platform. In a second step, the coelectrodeposition of sodium alginate and hemoglobin as drug delivery system and a drug model, respectively, onto the Co-Ni porous films will be studied. The fabrication process, the morphology, thickness and roughness, the magnetic properties as well as drug delivery studies, will be investigated.

\section{Experimental section}

\section{Co-Ni porous films preparation and characterization}

Co-Ni 3D porous films were prepared from different solutions containing $\mathrm{CoCl}_{2} \cdot 6 \mathrm{H}_{2} \mathrm{O}$ (Panreac p.a.), $\mathrm{NiCl}_{2} \cdot 6 \mathrm{H}_{2} \mathrm{O}$ (Sigma Aldrich, p.a. $\geq 98 \%$ ), $\mathrm{H}_{3} \mathrm{BO}_{3}$ (Merk p.a.) and $\mathrm{NH}_{4} \mathrm{Cl}(\mathrm{AC}$, p.a.), all reagents being of analytical grade. The solutions were freshly prepared with water first double-distilled and then treated with a Millipore Milli-Q system. The $\mathrm{pH}$ was adjusted in the range 1-3 with $\mathrm{HCl}$ and the temperature was maintained at $25^{\circ} \mathrm{C}$. Solutions were de-aerated by argon bubbling before each experiment and maintained under argon atmosphere during it.

Electrochemical experiments were performed in a conventional three-electrode cell using an Autolab with PGSTAT30 and GPES software. Si/Ti(10 nm)/Ni (100nm) substrates were employed as working electrode. Si/Ti/Ni was cleaned with acetone, ethanol and rinsed in water 
before deposition. The reference electrode was an $\mathrm{Ag} / \mathrm{AgCl} / 3 \mathrm{M} \mathrm{KCl}$ electrode. All potentials were referred to this electrode. The counter electrode was a platinum spiral.

Film morphology was observed using Hitachi H-4100 FE field emission scanning electron microscope (FE-SEM). Thickness was analyzed by confocal microscopy using a Leica DCM 3D interferometer (Germany). The films prepared had a thickness of $2 \mu \mathrm{m}$. Elemental composition was determined with X-ray fluorescence using X-ray Flourescence Fisherscope system XDAL equipment and WINFTM19 software.

\section{Co-electrodeposition of alginate and hemoglobin and characterization}

Alginate films were prepared electrochemically from solutions containing sodium alginate (Sigma-Aldrich, 1 wt.\%), $\mathrm{K}_{2} \mathrm{SO}_{4}$ (Panreac, $0.1 \mathrm{M}$ ) and $\mathrm{CaCO}_{3}$ (Panreac, 0.5 wt.\%) in suspension. Hemoglobin was added to the solution as a drug test (2-8 wt.\%). These experiments were performed in a conventional three-electrode cell using an Autolab with PGSTAT30 and GPES software. Co-Ni 3D porous films previously obtained were employed as working electrode. The reference electrode was an $\mathrm{Ag} / \mathrm{AgCl} / 3 \mathrm{M} \mathrm{KCl}$ electrode and the counter electrode was a platinum spiral. The area of the working electrode was set from 0.25 to $1 \mathrm{~cm}^{2}$.

In vitro release of hemoglobin entrapped into alginate matrix during electrodeposition was performed for a minimum of 5 samples. Dried samples were placed in a $0.1 \mathrm{M} \mathrm{NaCl}$ solution and allowed to swell and release the hemoglobin. At defined times some samples were collected and the presence of hemoglobin detected by the luminol test. 
Magnetic measurements were taken in a SQUID magnetometer at $300 \mathrm{~K}$ in helium atmosphere. The magnetization-magnetic field curves were recorded maintaining the samples parallel to the applied magnetic field.

\section{Results and Discussion}

\section{Co-Ni 3D porous films preparation and characterization}

Firstly, a cyclic voltammetric study of the electrolyte was performed in order to establish the potential and intensity range were the different either reduction or oxidation processes of both metallic ions take place. The electrolyte composition was selected taking into consideration not only the standard potentials of each metal $\left(\mathrm{E}_{\mathrm{Co}}{ }^{2+} / \mathrm{Co}=-0.499 \mathrm{~V} ; \mathrm{E}_{\mathrm{Ni}}{ }^{2+} / \mathrm{Ni}=-0.470 \mathrm{~V}\right)$ but also the anomalous codeposition of $\mathrm{Co}$ and $\mathrm{Ni}$, where the less noble metal (cobalt) is deposited easier: ${ }^{15}$ the favoured electrodeposition of $\mathrm{Co}$ in the Co-Ni system allowed us to select lower concentrations of $\mathrm{Co}(\mathrm{II})$ than $\mathrm{Ni}(\mathrm{II})$ to prepare $\mathrm{Co}-\mathrm{Ni}$ deposits with a significant percentages of the two metals. Cobalt increases de magnetization of saturation of the alloy whereas nickel improves the corrosion resistance of the material. ${ }^{16}$

Fig. 1 shows the cyclic voltammetry recorded from the $0.2 \mathrm{M} \mathrm{Co}(\mathrm{II})+0.9 \mathrm{M} \mathrm{Ni}(\mathrm{II})+0.5 \mathrm{M}$ $\mathrm{H}_{3} \mathrm{BO}_{3}$ solution at $\mathrm{pH}=3$. Voltammetric experiments were made under quiescent conditions. The scan was initiated at a controlled potential were no current was detected and towards negative potentials. A continuous current increase was observed at $-0.7 \mathrm{~V}$ corresponding to simultaneous cobalt and nickel reduction because of the closeness of their reductions potentials. On the other hand, a clear reduction peak was not observed because of hydrogen evolution took place at very close potential due to the electrocatalytic properties of the deposited metals. During the positive scan, just one oxidation peak was recorded attributed to cobalt and nickel oxidation as a result of a Co-Ni alloy formation. This result was expected in view of the Co-Ni 
phase diagram ${ }^{17}$ where $\mathrm{Co}$ and $\mathrm{Ni}$ are miscible. From these experiments, the potential window at which each process took place has been determined owing to establish potential ranges for film's electrodeposition. The reduction and oxidation reactions are depicted in Fig. 1.

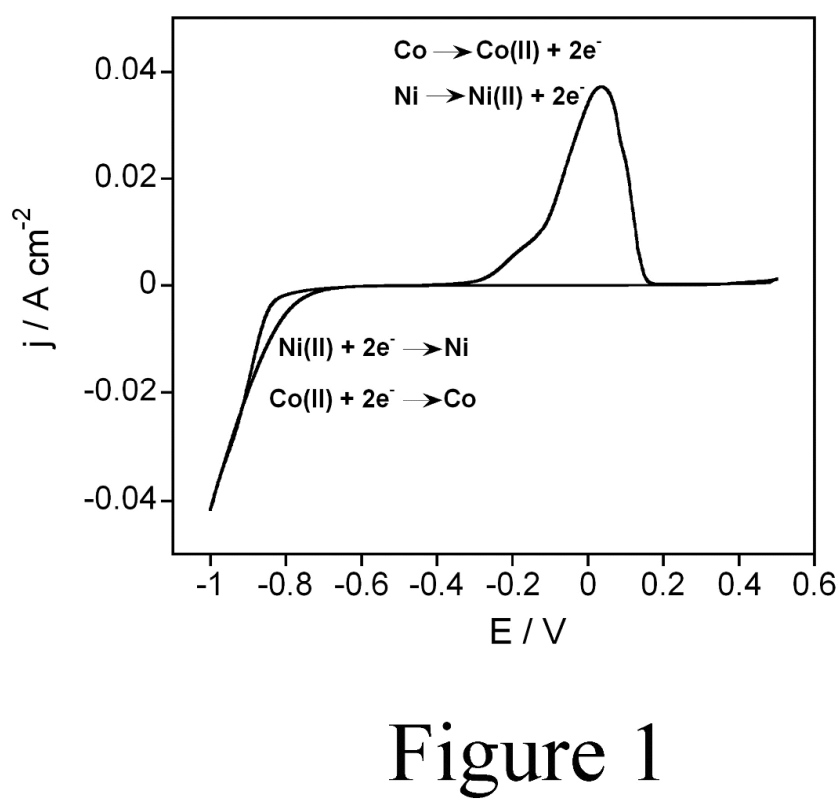

Fig. 1. Cyclic voltammetry of the solution $0.2 \mathrm{M} \mathrm{CoCl}_{2}+0.9 \mathrm{M} \mathrm{NiCl}_{2}+0.5 \mathrm{M} \mathrm{H}_{3} \mathrm{BO}_{3}(\mathrm{pH}=3)$.

Deposits were initially prepared potentiostatically over $\mathrm{Si} / \mathrm{Ti} / \mathrm{Ni}$ substrate and under stirring conditions in order to keep the contribution of the electroactive species throughout the electrode constant as well as to favour composition constancy along the thickness of the deposit. The applied potentials were more negative than that corresponding to the onset of nickel deposition in each solution. Fig. 2 shows some representative current density-time $(j-t)$ transients recorded during Co-Ni electrodeposition process. Under quiescent conditions and at low applied potentials (Fig. 2, Curve a), $j$-t transients show a first peak attributed to the alloy nucleation process, followed by a progressive current increase related to the alloy growth. As the applied potential was made more negative (Fig. 2, Curve b), the nucleation process is not observed 
because it takes at very short times and the $\mathrm{j} / \mathrm{t}$ slope is higher as a consequence of the higher deposition rate.

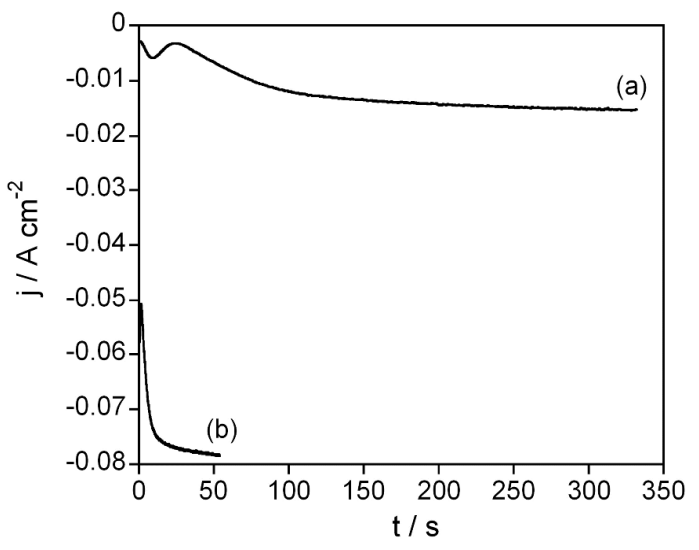

Figure 2

Fig. 2. $j / \mathrm{t}$ transients recorded from the solution $0.2 \mathrm{M} \mathrm{CoCl}_{2}+0.9 \mathrm{M} \mathrm{NiCl}_{2}+0.5 \mathrm{M} \mathrm{H}_{3} \mathrm{BO}_{3}(\mathrm{pH}$ = 3) at different potentials. a) $-800 \mathrm{mV}$, b) $-1000 \mathrm{mV}$. Substrate Si/Ti/Ni.

Fig. 3 shows the SEM micrographs of the deposits obtained in the whole potential range. Deposits obtained at more positive potentials are uniform and compact with acicular morphology (Fig. 3a). However, the grains are more faceted and smaller as the applied potential is made more negative because nucleation rate is higher (Fig. 3b). Moreover, the deposits lost its adherence when the applied potential was highly negative to favor hydrogen evolution to increase porosity into the films. On the other hand, a clear film composition-applied potential dependence was observed: nickel incorporation into the films increased as the applied potential was made more negative, due to the diffusion-controlled process for Co deposition and activation-controlled process for $\mathrm{Ni}$ deposition. ${ }^{18}$ 

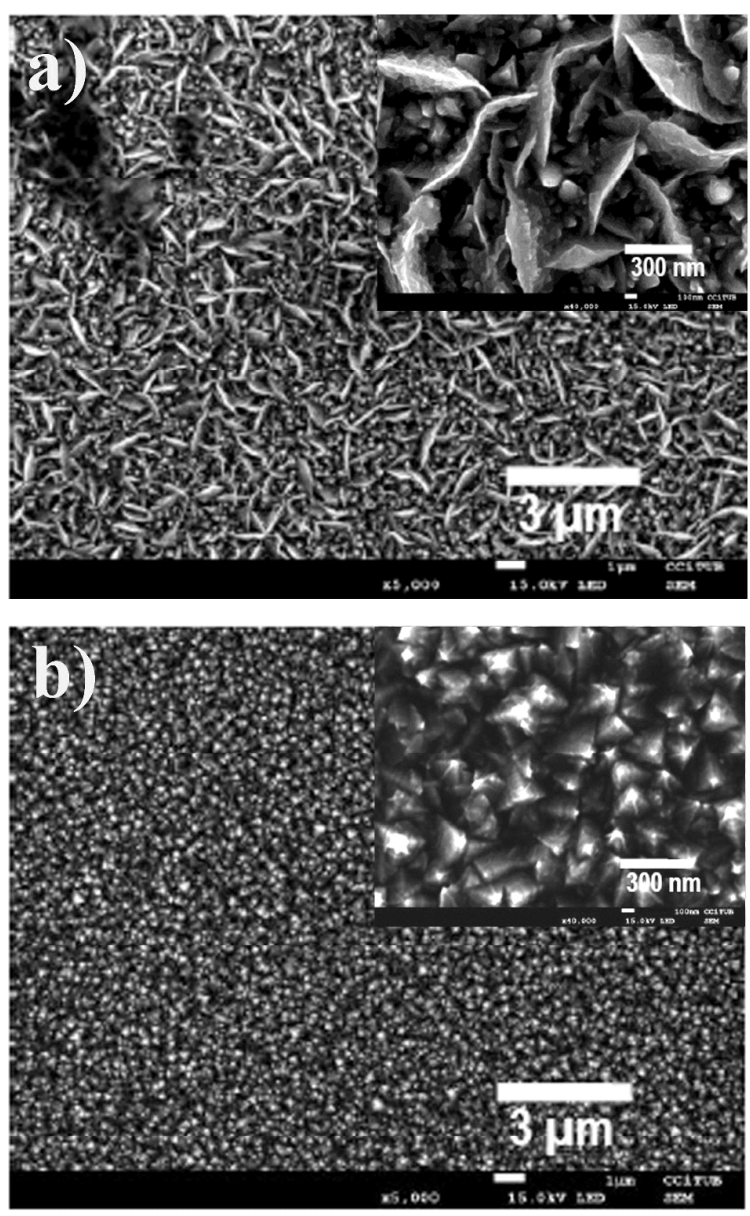

Figure 3

Fig. 3. SEM micrographs of deposits obtained by chronoamperometry from the solution $0.2 \mathrm{M}$ $\mathrm{CoCl}_{2}+0.9 \mathrm{M} \mathrm{NiCl}_{2}+0.5 \mathrm{M} \mathrm{H}_{3} \mathrm{BO}_{3}(\mathrm{pH}=3)$ at different applied potentials. a) $-800 \mathrm{mV}$, b) $1000 \mathrm{mV}$. Images corresponds with the curves in Fig. 2.

Alternatively, the deposits were prepared glavanostatically in order to have a better control of the deposition process. High current densities and short deposition times were applied in order to favor hydrogen evolution and hence porosity into the film. Fig. 4 shows some chronopotentiometric curves ( $E$-t transients) recorded during the deposition process. As it can be observed, the onset potential is more negative as the applied current density is made more negative. The obtained deposits were also observed by SEM (Fig. 5). Although the films 
showed an increased porosity regarding those obtained potentiostatically, they were characterized by poor adherence and poor uniformity.

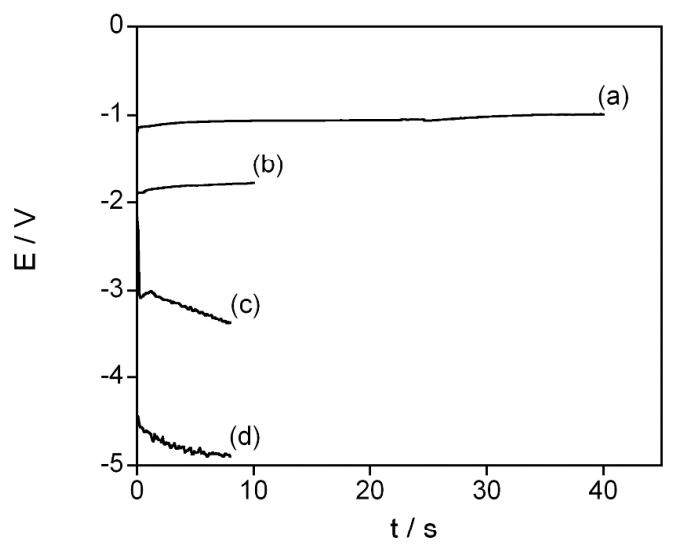

Figure 4

Fig. 4. $E / t$ transients recorded from the solution $0.2 \mathrm{M} \mathrm{CoCl}_{2}+0.9 \mathrm{M} \mathrm{NiCl}_{2}+0.5 \mathrm{M} \mathrm{H}_{3} \mathrm{BO}_{3}(\mathrm{pH}$ = 3) at different current densities. a) $-0.1 \mathrm{~A} \mathrm{~cm}^{-2}$, b) $\left.\left.-0.4 \mathrm{~A} \mathrm{~cm}^{-2}, \mathrm{c}\right)-0.5 \mathrm{~A} \mathrm{~cm}^{-2}, \mathrm{~d}\right)-1 \mathrm{~A} \mathrm{~cm}^{-2}$.

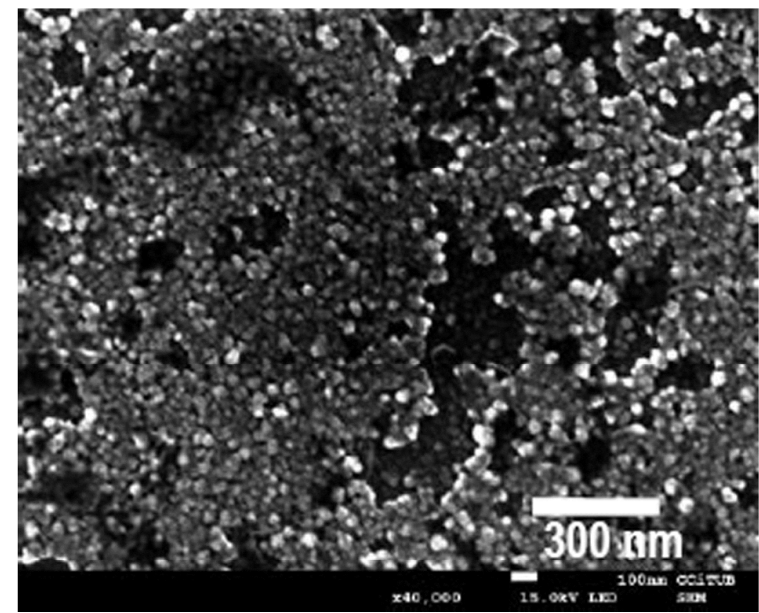

\section{Figure 5}

Fig. 5. SEM micrograph of a deposit obtained by chronopotentiometry from the solution $0.2 \mathrm{M}$ $\mathrm{CoCl}_{2}+0.9 \mathrm{M} \mathrm{NiCl}_{2}+0.5 \mathrm{M} \mathrm{H}_{3} \mathrm{BO}_{3}(\mathrm{pH}=3)$ at $-1 \mathrm{~A} \mathrm{~cm}^{-2}$. 
In order to try to improve the porosity, homogeneity and adherence of the films, ammonium chloride was used as additive. By adding $\mathrm{NH}_{4}{ }^{+}$ions to the electrolyte, the amount of $\mathrm{H}^{+}$can be increased. It was also shown in Ref. ${ }^{19}$ that at high current densities the discharge of $\mathrm{NH}_{4}{ }^{+}$on the electrode results in the production of atomic hydrogen adsorbed to the electrode, which should produce molecular hydrogen. Moreover, $\mathrm{pH}$ of the electrolyte was also modified in order to favor hydrogen evolution. Table 1 shows the current density of the different deposits obtained under variable concentrations of $\mathrm{NH}_{4} \mathrm{Cl}$ and $\mathrm{pH}$.

\begin{tabular}{cccc}
\hline$j / \mathrm{A} \mathrm{cm}^{-2}$ & $\mathrm{pH}$ & {$\left[\mathrm{NH}_{4} \mathrm{Cl}\right] / \mathrm{M}$} & $\mathrm{Co} / \mathrm{wt} . \%$ \\
\hline 3 & 3 & 0 & 6.1 \\
4 & 1 & 0 & 3.0 \\
5 & 3 & 0.2 & 16.0 \\
6 & 1 & 0.4 & 51.4 \\
7 & 1 & 0.4 & 45.4 \\
8 & 1 & 0.4 & 42.2 \\
9 & 1 & 0.4 & 40.3 \\
10 & 1 & 0.4 & 39.2 \\
\hline
\end{tabular}

Table 1. Dependence of the cobalt content into the Co-Ni films with current density $(j), \mathrm{pH}$ and $\mathrm{NH}_{4} \mathrm{Cl}$ concentration into the electrolyte.

In the absence of ammonium chloride, the application of very negative current densities implies the formation of deposits with very low cobalt percentages. However, the presence of $\mathrm{NH}_{4} \mathrm{Cl}$ favors the formation of deposits with significant cobalt contents, even at the most negative current densities used. In order to understand this phenomenon, the speciation of the electroactive species into the solution was carried out using Hidra-Medusa software. ${ }^{20}$ The speciation diagram show that while the Co(II) content remained constant independently of $\mathrm{NH}_{4} \mathrm{Cl}$ concentration, $\mathrm{Ni}(\mathrm{II})$ content decreased, probably by complexation with chloride anions. Thus, the higher the $\mathrm{NH}_{4} \mathrm{Cl}$ is the lower the $\mathrm{Ni}$ deposition rate is and the higher the cobalt content into the films. On the other hand, SEM observation of the different films allows observing that the addition of $\mathrm{NH}_{4} \mathrm{Cl}$ increased the compactness and improved the adherence of 
the deposit to the substrate, even for the deposits obtained at $\mathrm{pH}=3$. On the other hand, the $\mathrm{pH}$ decrease led to an increase in the film porosity as a consequence of a higher hydrogen evolution. The porosity of the films was higher as the applied potential was more negative (Fig. 6). Thus, the best conditions that allowed obtaining 3D porous Co-Ni films were from the electrolyte 0.2 $\mathrm{M} \mathrm{CoCl}_{2}+0.9 \mathrm{M} \mathrm{NiCl}_{2}+0.5 \mathrm{M} \mathrm{H}_{3} \mathrm{BO}_{3}+0.4 \mathrm{M} \mathrm{NH}_{4} \mathrm{Cl}$ at $\mathrm{pH}=1$. Moreover, highly negative applied current densities (> $\left.3 \mathrm{~A} \mathrm{~cm}^{-2} \mid\right)$ were needed to allow both Co-Ni codeposition and hydrogen evolution, the last acting as template.
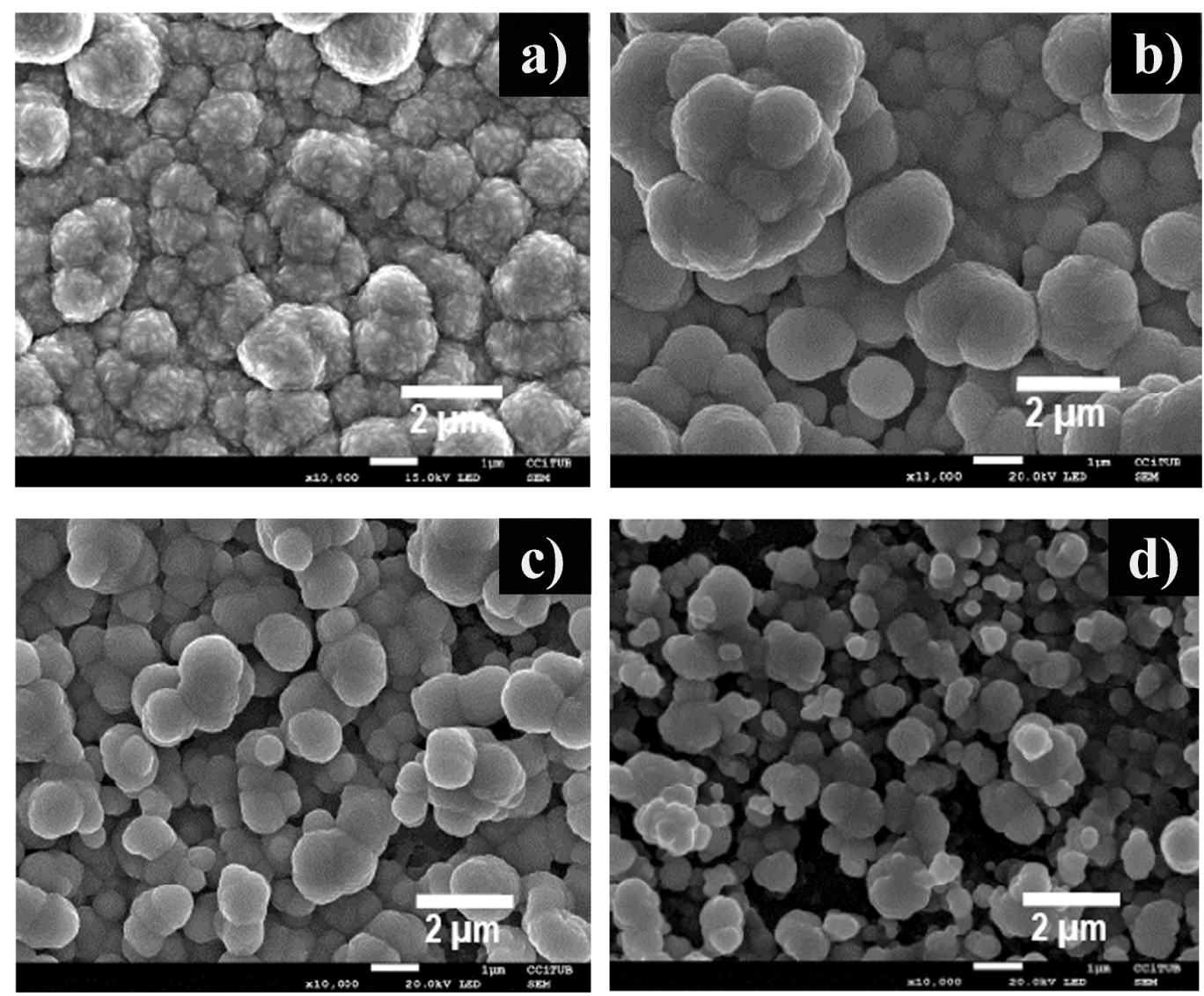

\section{Figure 6}

Fig. 6. SEM microcraphs of deposits obtained by chornoamperometry from the solution $0.2 \mathrm{M}$ $\mathrm{CoCl}_{2}+0.9 \mathrm{M} \mathrm{NiCl}_{2}+0.5 \mathrm{M} \mathrm{H}_{3} \mathrm{BO}_{3}+0.4 \mathrm{M} \mathrm{NH}_{4} \mathrm{Cl}(\mathrm{pH}=1)$ at different applied current densities. a) $-1 \mathrm{~A} \mathrm{~cm}^{-2}$, b) $-2 \mathrm{~A} \mathrm{~cm}^{-2}$, c) $-3 \mathrm{~A} \mathrm{~cm}^{-2}$, d) $-4 \mathrm{~A} \mathrm{~cm}^{-2}$. 


\section{Co-electrodeposition of alginate and hemoglobin. Characterization of the hybrid material.}

Once the conditions of the preparation of 3D porous Co-Ni films were optimized, the electrodeposition of alginate onto the Co-Ni films was studied. We selected electrodeposition rather than electrophoretic deposition because of faster deposition rates and lower applied potentials are needed to prepare the alginate films. The electrolyte employed to perform the electrodeposition is: 1 wt. $\%$ sodium alginate, $0.1 \quad \mathrm{M} \mathrm{K}_{2} \mathrm{SO}_{4}$ and 0.5 wt.\% $\mathrm{CaCO}_{3}$ (in suspension). The mechanism responsible for the anodic electrodeposition of alginate starts with the generation of protons at the anode surface due to water electrolysis (Eq. 1). These protons immediately react with the suspended $\mathrm{CaCO}_{3}$ particles releasing $\mathrm{Ca}^{2+}$ ions (Eq. 2). Finally, these locally generated $\mathrm{Ca}^{2+}$ ions interact with alginate chains inducing their cross-linking onto the substrate (Eq. 3). ${ }^{21}$ The reactions taking place during this process are:

$$
\begin{aligned}
& 2 \mathrm{H}_{2} \mathrm{O}(\mathrm{aq}) \rightarrow \mathrm{O}_{2}(\mathrm{~g})+4 \mathrm{H}^{+}(\mathrm{aq})+4 \mathrm{e}^{-} \quad(1) \\
& \mathrm{H}^{+}(\mathrm{aq})+\mathrm{CaCO}_{3}(\mathrm{~s}) \rightarrow \mathrm{Ca}^{2+}(\mathrm{aq})+\mathrm{H}_{2} \mathrm{O}(\mathrm{aq})+\mathrm{CO}_{2}(\mathrm{~g}) \\
& \left.2\left(\mathrm{C}_{12} \mathrm{H}_{14} \mathrm{Na}_{2} \mathrm{O}_{12}\right)_{\mathrm{n}}(\mathrm{s})+2 \mathrm{Ca}^{2+}(\mathrm{aq}) \rightarrow \mathrm{C}_{12} \mathrm{H}_{14} \mathrm{O}_{12}\right)_{\mathrm{n}^{-}}-2 \mathrm{Ca}^{2+}-\left(\mathrm{C}_{12} \mathrm{H}_{14} \mathrm{O}_{12}\right)_{\mathrm{n}}+4 \mathrm{Na}^{+}
\end{aligned}
$$

Cyclic voltammetry experiments were first performed in order to study the potential range at which the different electrochemical processes take place. The substrate employed was the 3D porous Co-Ni films previously deposited. Cyclic voltammetry was initiated at $-0.5 \mathrm{~V}$ going first toward positive potentials (Fig. 7). The scan was reverse at $1.5 \mathrm{~V}$ up to $-0.5 \mathrm{~V}$. As it can be observed in this figure, there are two oxidation processes: one peak centered at $-0.9 \mathrm{~V}$ probably attributed to partial Co-Ni oxidation followed by water oxidation. From this study, potentials higher than $1.5 \mathrm{~V}$ were selected to allow the deposition of alginate onto the substrate. 


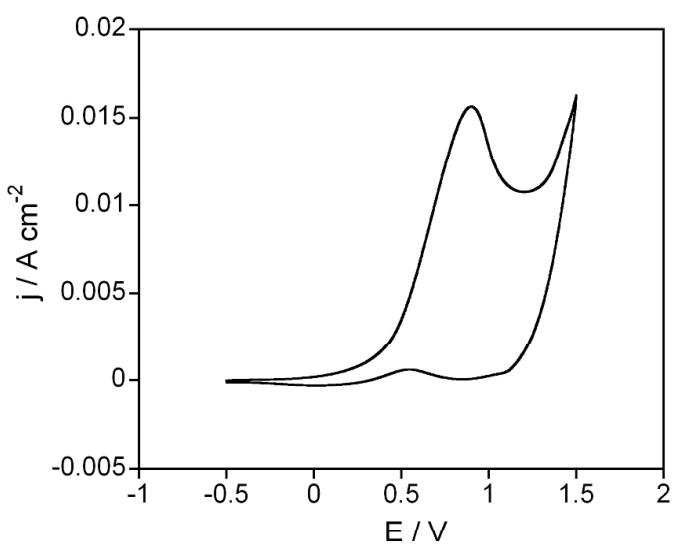

Figure 7

Fig. 7. Cyclic voltammetry of the solution 1 wt. $\%$ sodium alginate $+0.1 \mathrm{M} \mathrm{K}_{2} \mathrm{SO}_{4}+0.5$ wt. $\%$ $\mathrm{CaCO}_{3}$.

After that, alginate layers were grown potentiostatically for different applied potentials (from 1.8 to $7.2 \mathrm{~V}$ ) and different times (from 100 to $300 \mathrm{~s}$ ). Fig. 8 shows a $j$-t transient recorded during the deposition of alginate at $1.8 \mathrm{~V}$. The most remarkable feature is the highly positive current density because of the fast water oxidation process, it being higher as the applied potential was made more positive. In all cases it could be observed by eye oxygen evolution during the whole process. Finally, alginate was retained onto the porous Co-Ni substrates at the end of the deposition process (Fig. 9). It is interesting to remark at this point that when the deposition experiments were repeated onto thin and non-porous Co-Ni substrates, alginate matrix was not retained onto them. This result indicates that porous $\mathrm{Co}-\mathrm{Ni}$ films are essential to retain the alginate matrix onto a magnetic film. 


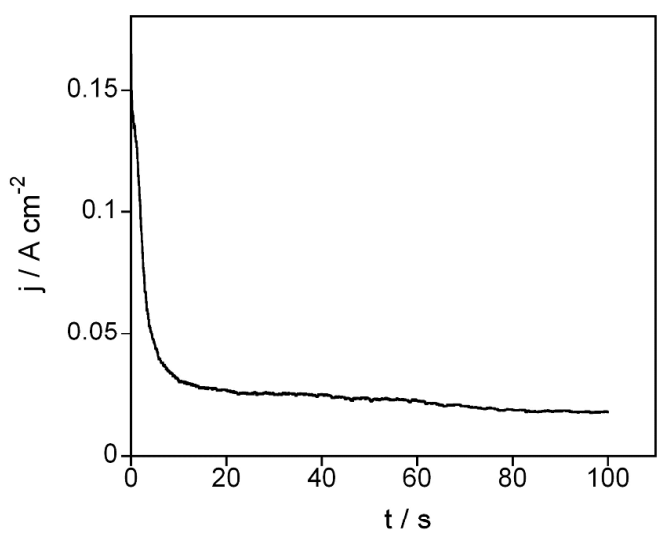

Figure 8

Fig. 8. $j / \mathrm{t}$ transient of the deposition of alginate from the solution $1 \mathrm{wt} . \%$ sodium alginate +0.1 $\mathrm{M} \mathrm{K}_{2} \mathrm{SO}_{4}+0.5$ wt. $\% \mathrm{CaCO}_{3}$. Applied potential $=1.8 \mathrm{~V}$.

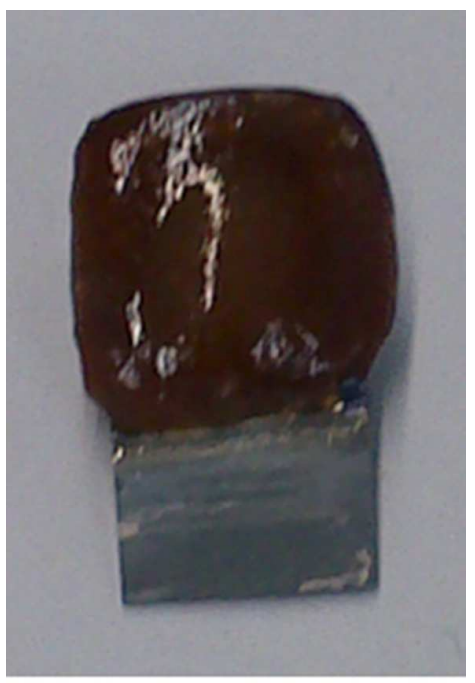

Figure 9

Fig. 9. Image of alginate matrix retained onto a 3D porous Co-Ni film. 
Once the conditions for alginate deposition were controlled, hemoglobin was added to the previous electrolyte as a test drug. Hemoglobin, a globular protein present in our blood and responsible to transport oxygen throughout the body, was selected because of its easy detection. The same chronoamperometric experiments than those previously performed from the hemoglobin-free electrolyte were made. The $j$-t transients showed the same profile and the alginate cross-linking was achieved. Moreover, it could also be observed that hemoglobin was retained into the alginate matrix because it acquired a pink color. The reason for its retention is that the electrodeposition of alginate is carried out at a $\mathrm{pH}$ below the isoelectric point of hemoglobin $(\mathrm{pH}=6.8-7){ }^{22}$ Thus, hemoglobin is positively charged being able to migrate towards the working electrode (negative electrode).

In order to study the viability of the Co-Ni/alginate-hemoglobin hybrid material as a microrobotic system wirelessly steered by a magnetic manipulation system, the magnetic properties of the hybrid material were examined. Fig. 10 shows the normalized magnetizationmagnetic field curves of the Co-Ni porous films (Fig. 10, continuous line) and the CoNi/alginate-hemoglobin hybrid materials (Fig. 10, dotted line). The magnetic curves show a clear soft ferromagnetic behavior of both materials with coercive field $\left(H_{\mathrm{C}}\right)$ values of 42 and 50 Oe for the Co-Ni and Co-Ni/alginate-hemoglobin materials, respectively (Inset Fig. 10). From the magnetic results one can infer that although some surface oxidation of the Co-Ni porous films may occur during alginate deposition as a consequence of the positive potentials applied, the Co-Ni films are not greatly affected showing magnetism. Thus, the hybrid materials could be used as microrobotic system manipulated by a magnetic field. On the other hand and based on the $H_{\mathrm{C}}$ values, the authors confirm that the crystalline structure of the Co-Ni films is facecentered cubic. Co-Ni films obtained from chloride-based electrolytes can show different crystalline structures depending on the electrodeposition conditions. ${ }^{23-25}$ While hcp (hexagonalclose packed) structure is obtained when very low deposition potentials are applied; fcc 
structure is observed at high potential values. The $H_{\mathrm{C}}$ values of hcp Co-Ni films are clearly higher than those of fcc Co-Ni.

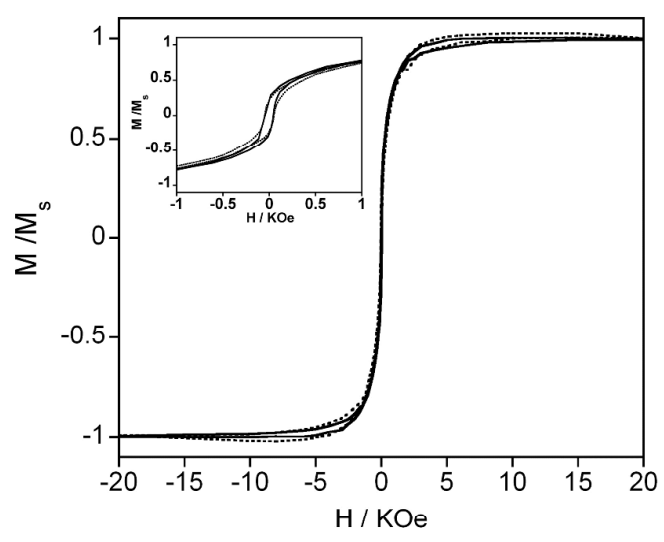

Figure 10

Fig. 10. Normalized magnetization-magnetic field curves of continuous line) Co-Ni films, dotted line) Co-Ni/alginate hybrid materials. Inset shows the coercive field of both films.

Finally, the study of hemoglobin release from the alginate matrix was performed to evaluate the suitability of the hybrid material as a drug delivery carrier. Samples were immersed in $0.1 \mathrm{M}$ $\mathrm{NaCl}$ solution at $37^{\circ} \mathrm{C}$ and allowed to swell and release hemoglobin. At defined times the solvent volumes were collected and analyzed by the luminol test. This test is based on the chemiluminescence reaction of luminol (3-Aminophthalhydrazide) with an oxidizing agent in a basic media and under the presence of oxygen. ${ }^{26}$ In our study, the iron from hemoglobin serves as a catalyst for the chemiluminescence reaction that causes luminol to glow. Moreover, the blue glow is iron concentration time-dependent. Thus, the concentration of hemoglobin can be monitored through the chemiluminescence time before fading. The release profiles of hemoglobin from alginate matrixes are shown in Fig. 11. The chemiluminescence time at fading against sample collection time are represented for the hybrid materials obtained at different applied potentials for alginate-hemoglobin codeposition. As it can be observed, in all cases 
hemoglobin release is higher as immersion time is higher, indicating that the release of hemoglobin is continuous with time. However, different profiles and kinetic of hemoglobin release are observed. While at low applied potentials (Fig. 11, curves a and b) the release profile follows an exponential behavior; at higher applied potentials the release profile follows a logarithmic equation (Fig. 11, curve c). The reason could be the more porous structure of the alginate matrix obtained at the most positive potential allowing the release of hemoglobin at shorter times.

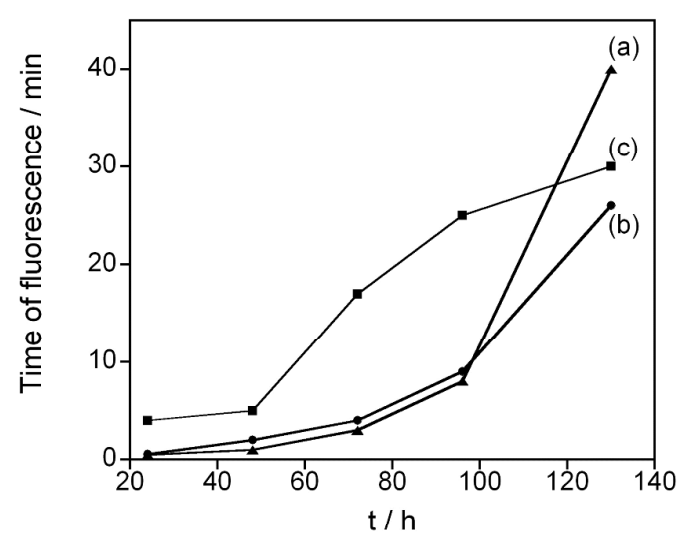

Figure 11

Fig. 11. Hemoglobin release profiles from Co-Ni/alginate hybrid materials. Alginate matrix was deposited at different applied potentials. a) $2.2 \mathrm{~V}$, b) $3.5 \mathrm{~V}$, c) $4.8 \mathrm{~V}$.

\section{Conclusions}

The authors report the preparation of Co-Ni/Alginate-hemoglobin hybrid materials for drug delivery applications and wireless controlled. The optimization of the electrodepostion conditions has allowed obtaining 3D porous Co-Ni films with high adherence and uniformity. Low $\mathrm{pH}$ values and $\mathrm{NH}_{4} \mathrm{Cl}$ presence into the electrolyte are beneficial to obtain a porous structure. After that, alginate was electrodeposited onto the previously prepared Co-Ni films by 
applying positive potential. Hemoglobin was retained inside the biopolymer matrix during the electrodeposition process. The magnetic properties of the hybrid material showed a softmagnetic behavior indicating its viability as a steerable magnetic device. Moreover, the release of hemoglobin from alginate with time indicates its suitability as a drug delivery platform.

\section{Acknowledgements}

This paper was supported by contract CTQ2010-20726 (subprogram BQU) from the Comision Interministerial de Ciencia y Tecnología (CICYT). The authors wish to thank the Centres Científics $i$ Tecnològics de la Universitat de Barcelona (CCiTUB) for the use of their equipment.

\section{References}

1. S. Ghosh and O. Inganase, Adv. Mater., 1999, 11, 1214-1218.

2. Y. Liu, S. Zha and M. Liu, Adv. Mater., 2004, 16, 256-260.

3. F. Scaglione, P. Rizzi and L. Battezzati, J. Alloys Compd., 2012, 536, S60-S64.

4. X.-H. Xia, J.-P. Tu, X.-L. Wang, C.-D. Gu and X.-B. Zhao, J. Mater. Chem., 2011, 21, 671679.

5. H.-C. Shin, J. Dong and M. Liu, Adv. Mater., 2003, 15(19), 1610-1614.

6. H.-C. Shin and M. Liu, Adv. Funct. Mater., 2005, 15 (4), 582-586.

7. S. Cherevko, X. Xing and C.-H. Chung, Electrochem. Commun., 2012, 12, 467-470.

8. J. Liu, L. Cao, W. Huang and Z. Li, Appl. Mater. Interf., 2011, 3, 3552-3558.

9. B.J. Nelson, I.K. Kaliakatsos and J.J. Abbott, Annu. Rev. Biomed. Eng., 2010, 12, 55-85. 
10. M. Kummer, J.J. Abbott, B. Kratochvil, R. Borer, A. Sengul and B.J. Nelson, IEEE. Trans. Rob., 2010, 26, 1006-1017.

11. S. Olver, J. Sánchez-Marcos, F.J. Palomares, E. Salas, E.M. Arc and P. Herrasti, Mater. Characteriz., 2014, 93, 79-86.

12. P. Cojocaru, L. Magagnin, E. Gomez, E. Valles, F. Liu, C. Carraro and R. Maboudian, J. Micromech. Microengineer., 2010, 20, 125017-125022.

13. D. Byrom, Biomaterials: Novel materials from biological sources, Stockton: New York, 1991.

14. K.Y. Lee and D.J. Mooney, Progr. Polymer Sci., 2012, 37(1), 106-126.

15. A. Brenner, Electrodeposition of Alloys, Academic Press: New York, 1963.

16. N.V. Myung and K. Nobe, J. Electrochem. Soc., 2001, 148, C136-C144.

17. H. Baker, Introduction to phase diagrams, alloy phase diagrams. ASM Handbook, ASM International: Cleveland, 1992.

18. E. Gomez, J. Ramirez and E. Valles, J. Appl. Electrochem., 1998, 28, 71-79.

19. C.A. Marozzi and A.C. Chialvo, Eletrochimica Acta, 2000, 45, 2111-2120.

20. Medusa software, http://www.kth.se/che/medusa/ (accessed September 2014).

21. Y. Cheng, X. Luo, J. Betz, G.F. Payne, W.E. Bentley and G.W. Rubloff, Soft matter, 2011, 7, 5677-5684.

22. T. Shiomi, M. Matsui, F. Mizukami and K. Sakaguchi, Biomaterials, 2005, 26, 5564-5571.

23. M. Duch, J. Esteve, E. Gómez, R. Pérez-Castillejos and E. Vallés, J. Electrochem. Soc. 2002, 149, C201-C208.

24. S. Pané, E. Gómez and E. Vallés, Electrochem. Comm. 2007, 9, 1755. 
25. J. Vilana, E. Gómez and E. Vallés, J. Electroanal. Chem., 2013, 703, 88-96.

26. E. Huntress, L. Stanley and A. Parker, J. Am. Chem. Soc., 1934, 56(1), 241-242.

\section{TABLE OF CONTENTS}

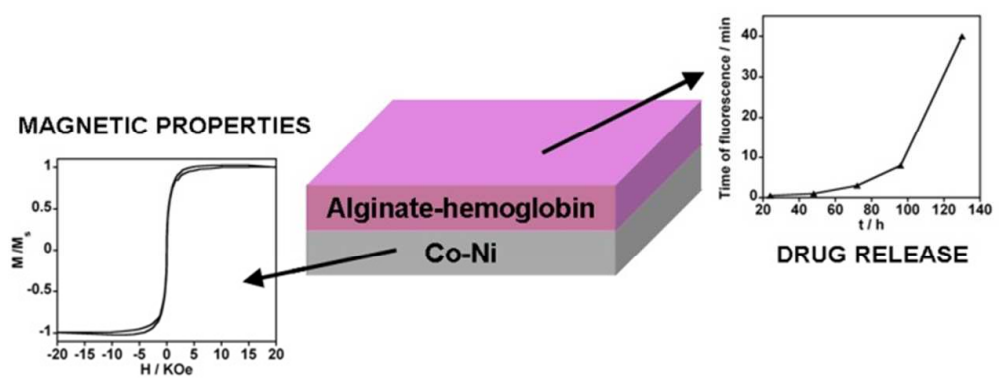

Three-dimensional porous $\mathrm{Co}-\mathrm{Ni}$ films/alginate hybrid materials have been successfully prepared by electrodeposition to be used as a steerable magnetic device for drug delivery applications. 


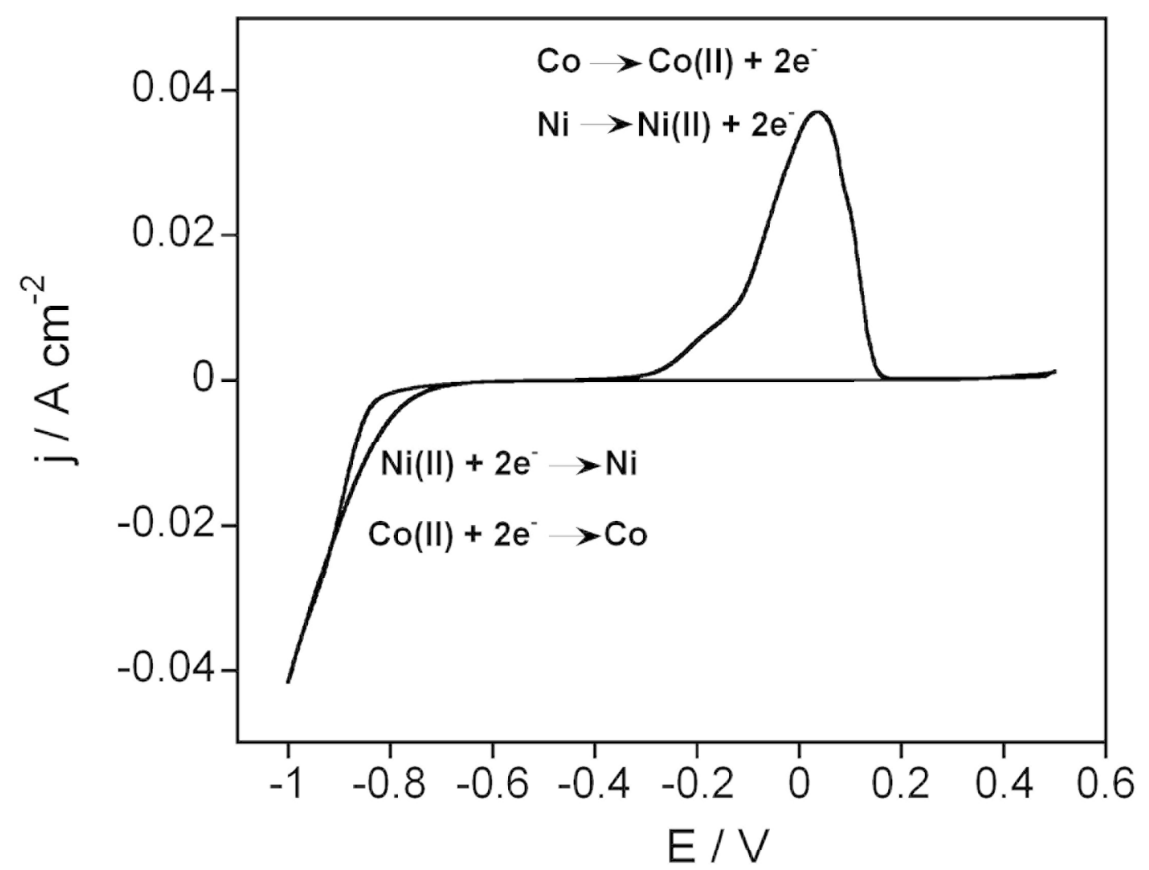

Figure 1 


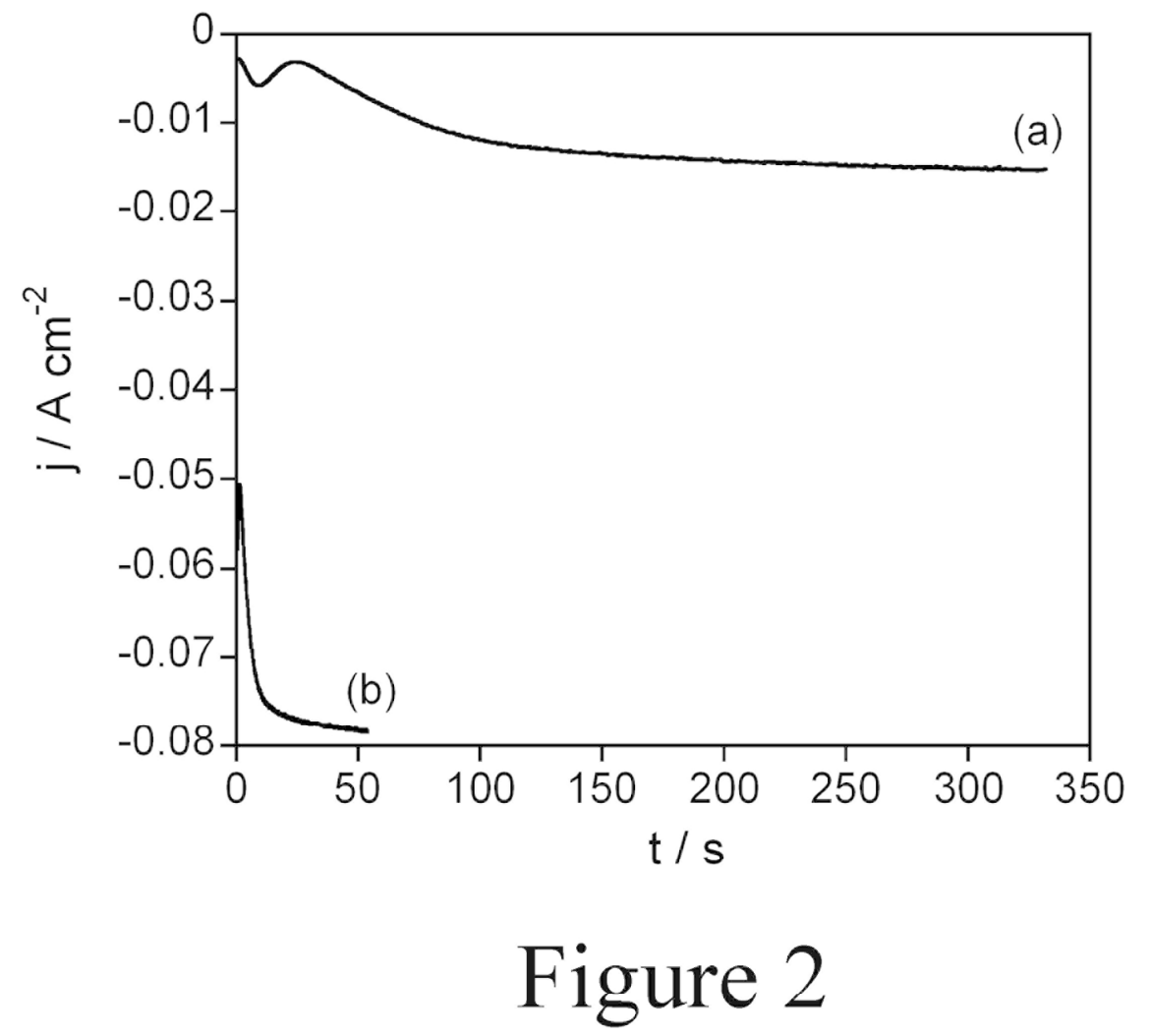



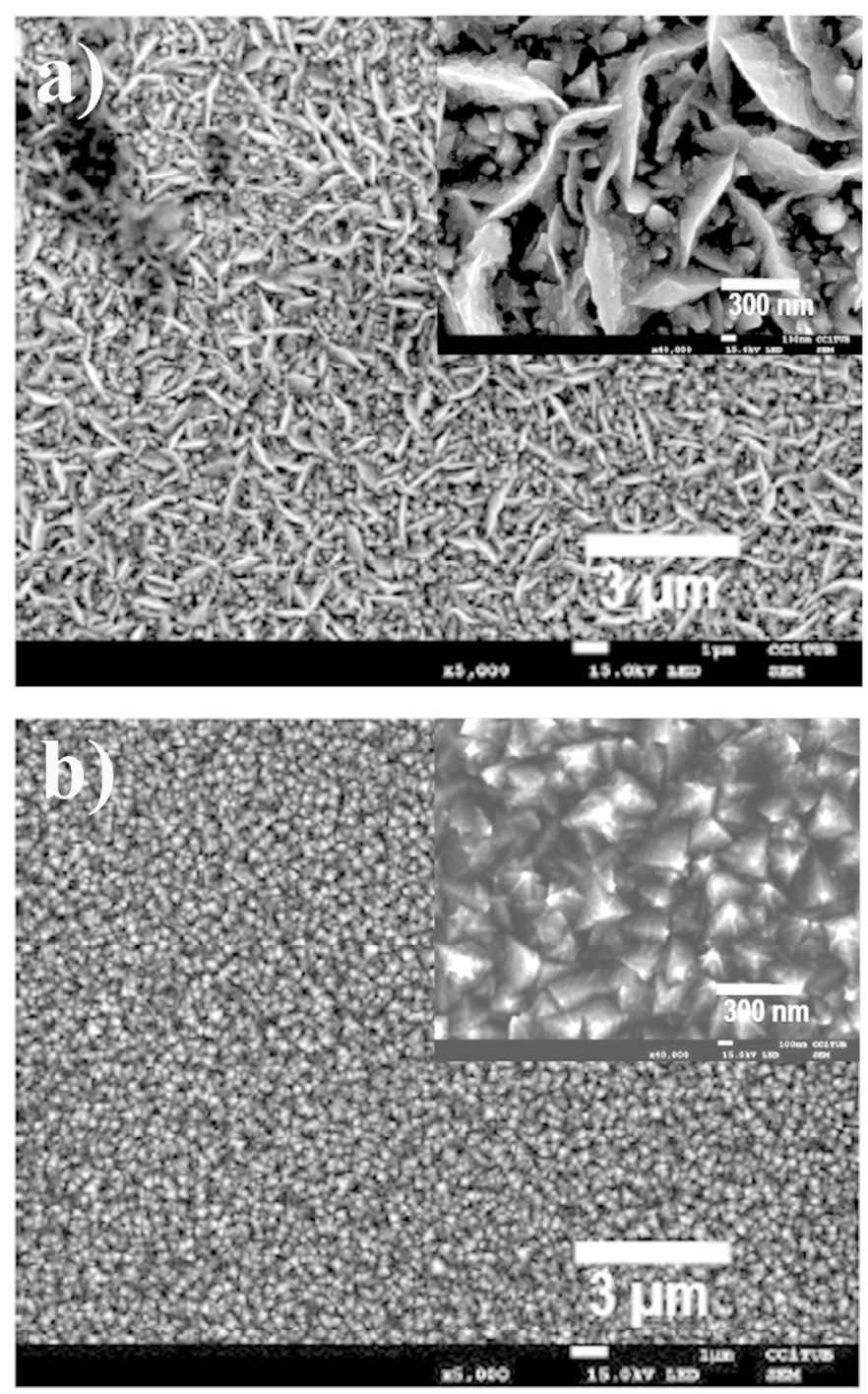

Figure 3 


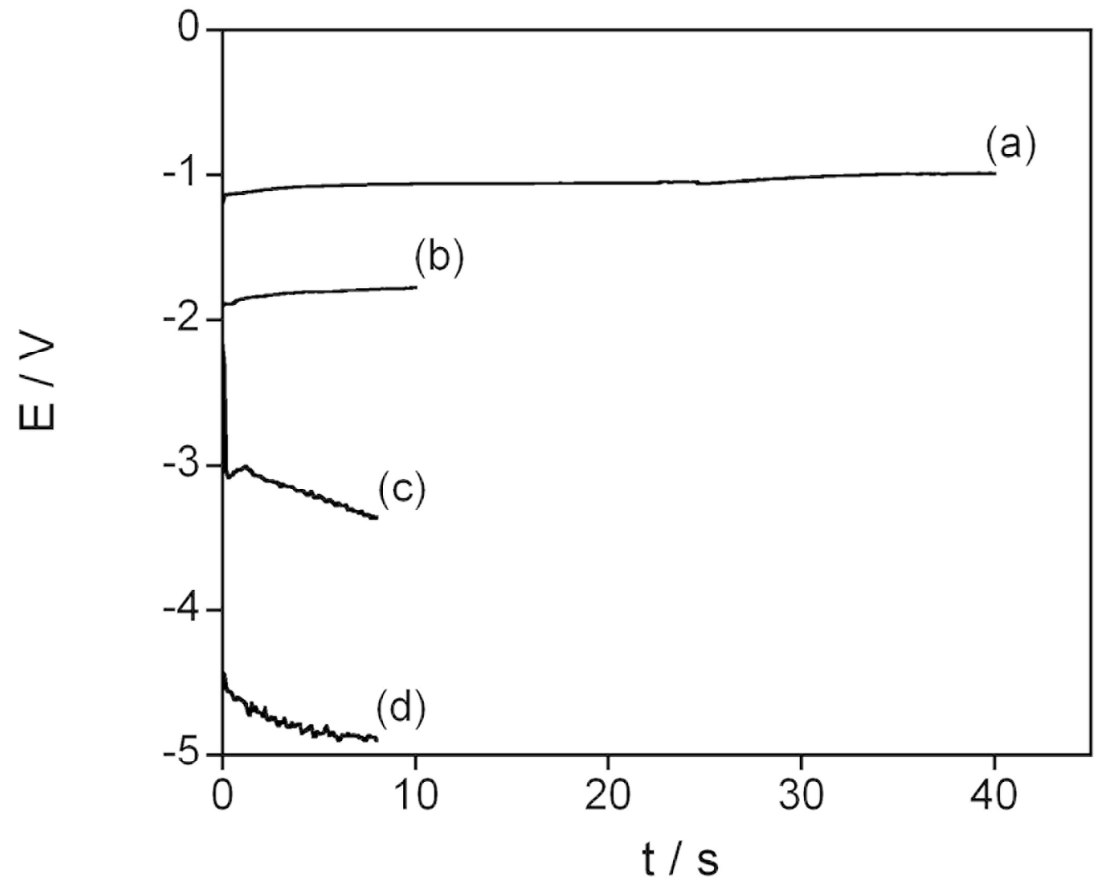

Figure 4 


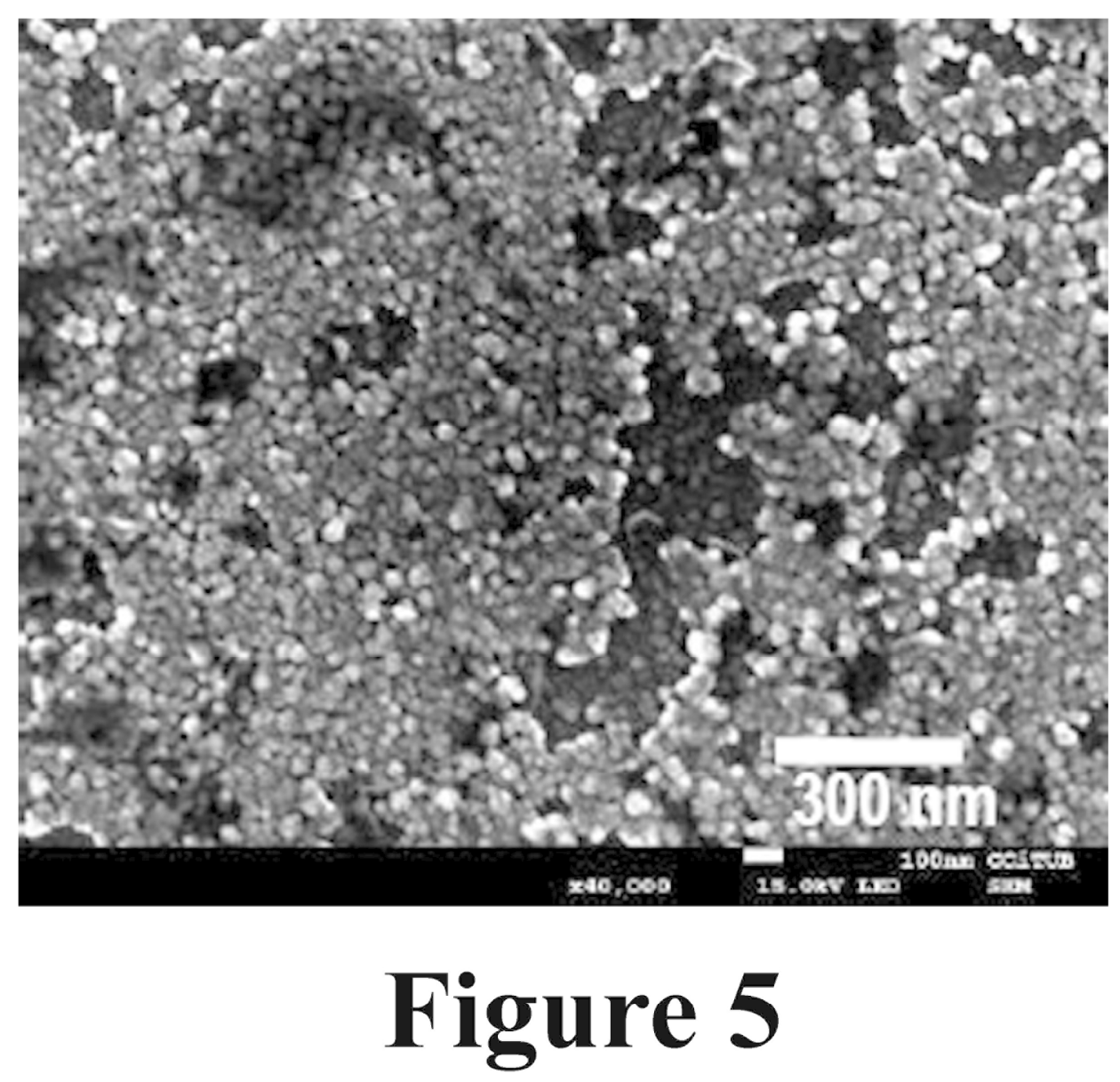



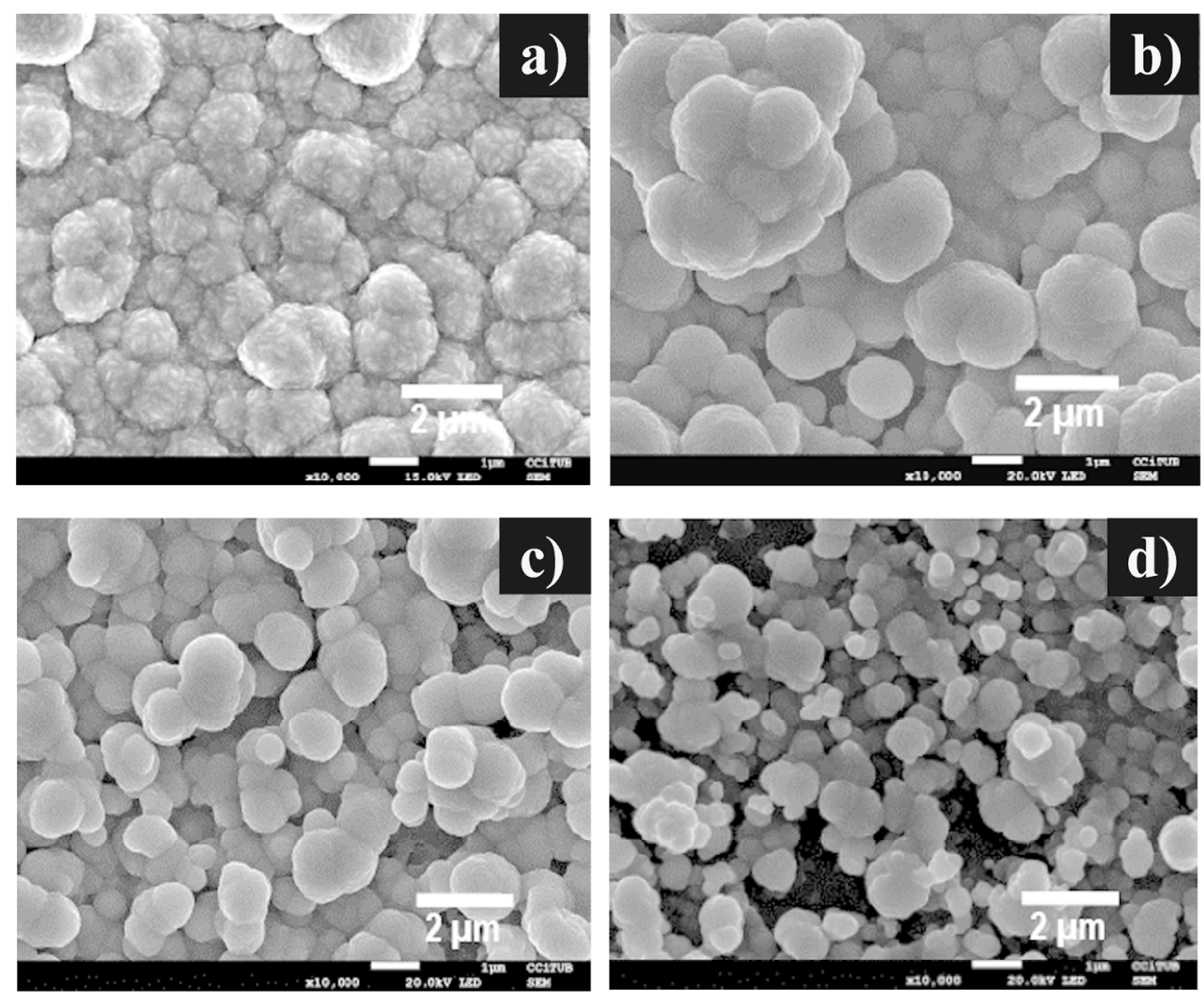

Figure 6 


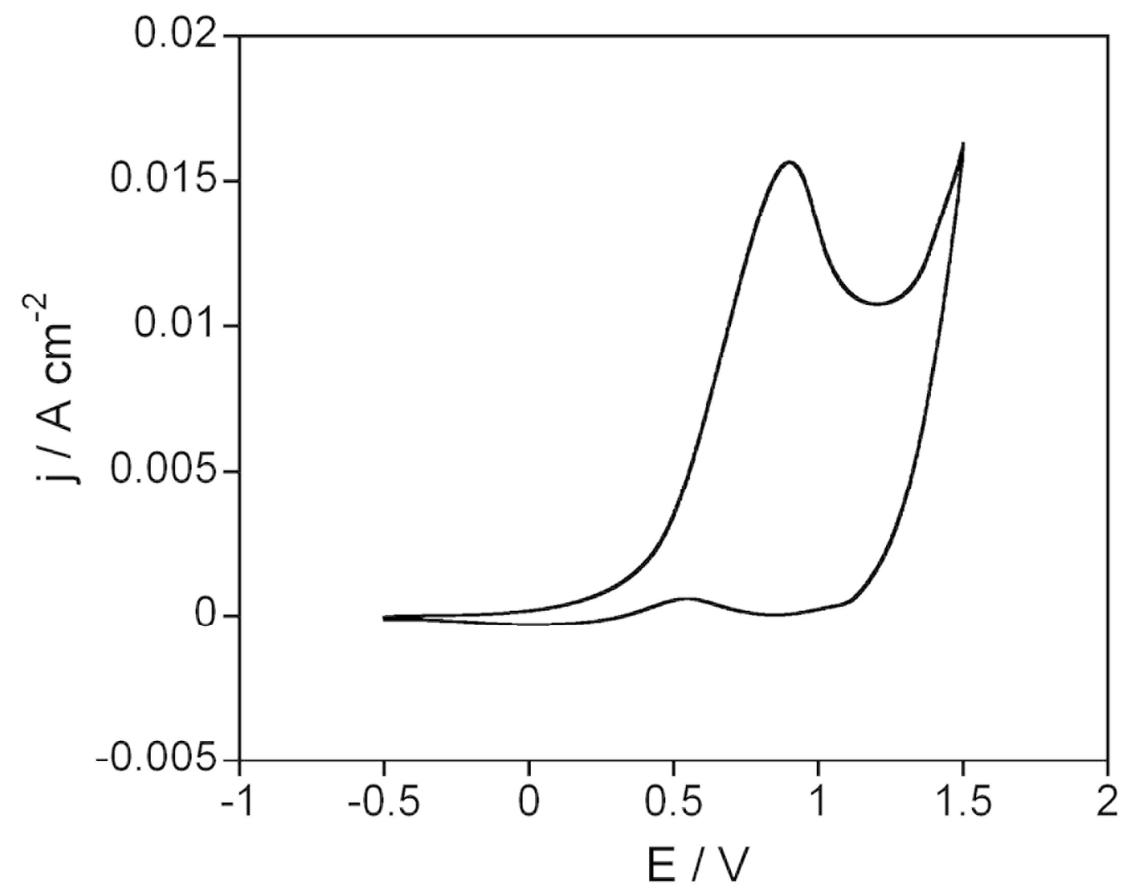

Figure 7 


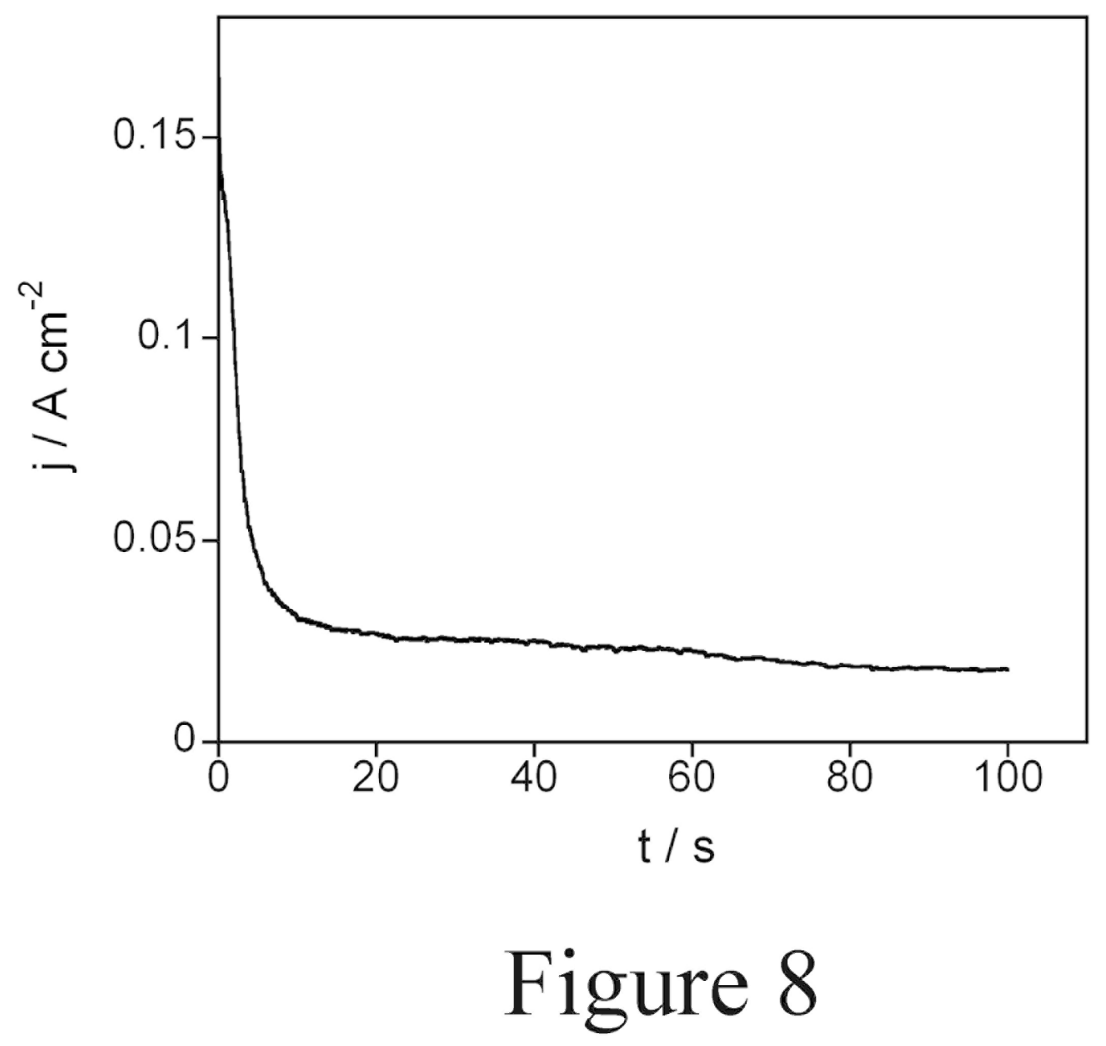




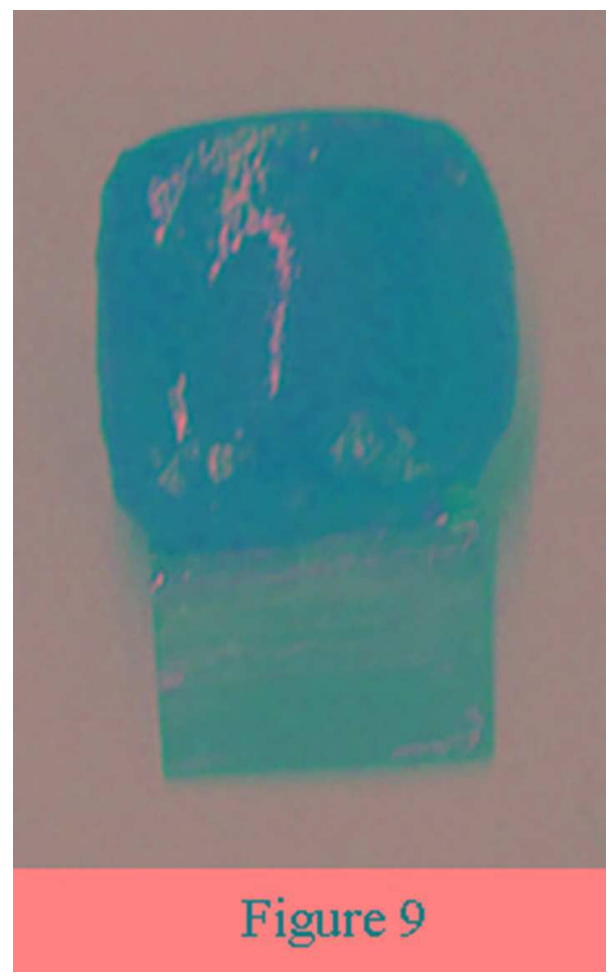

$80 \times 130 \mathrm{~mm}(72 \times 72 \mathrm{DPI})$ 


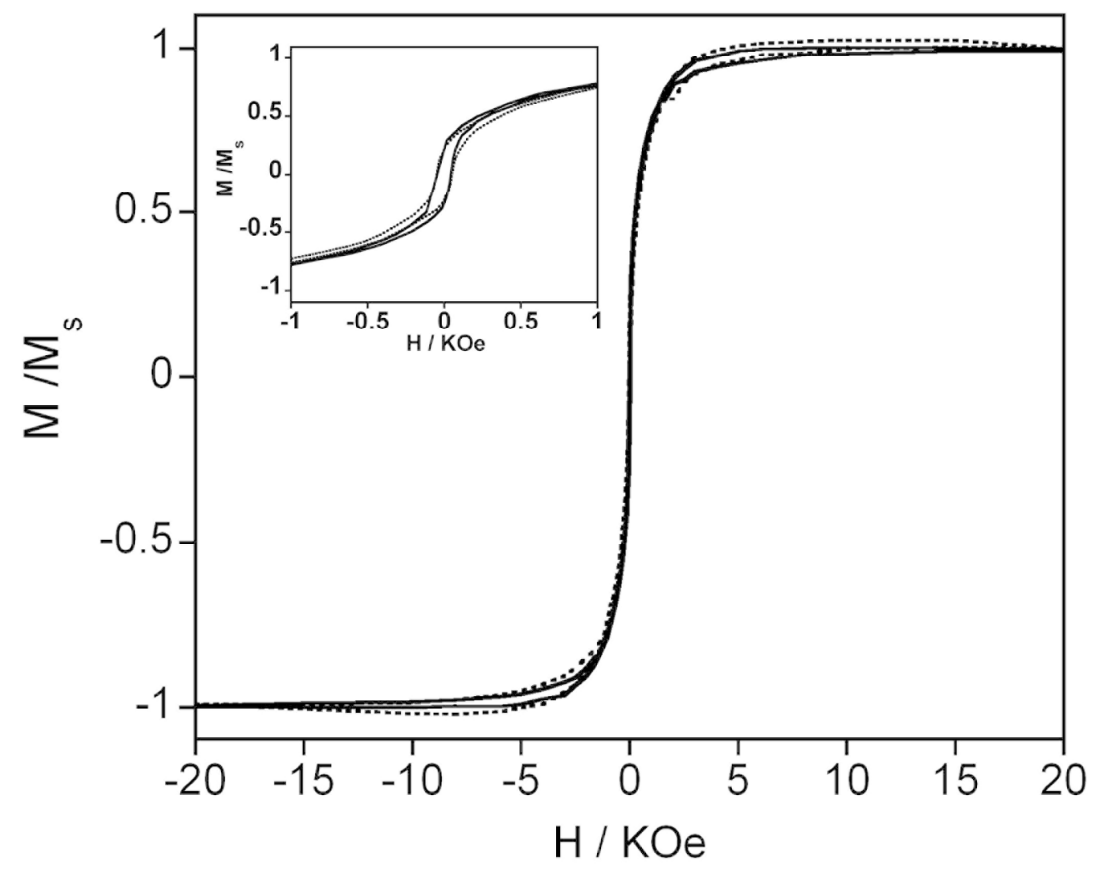

Figure 10 


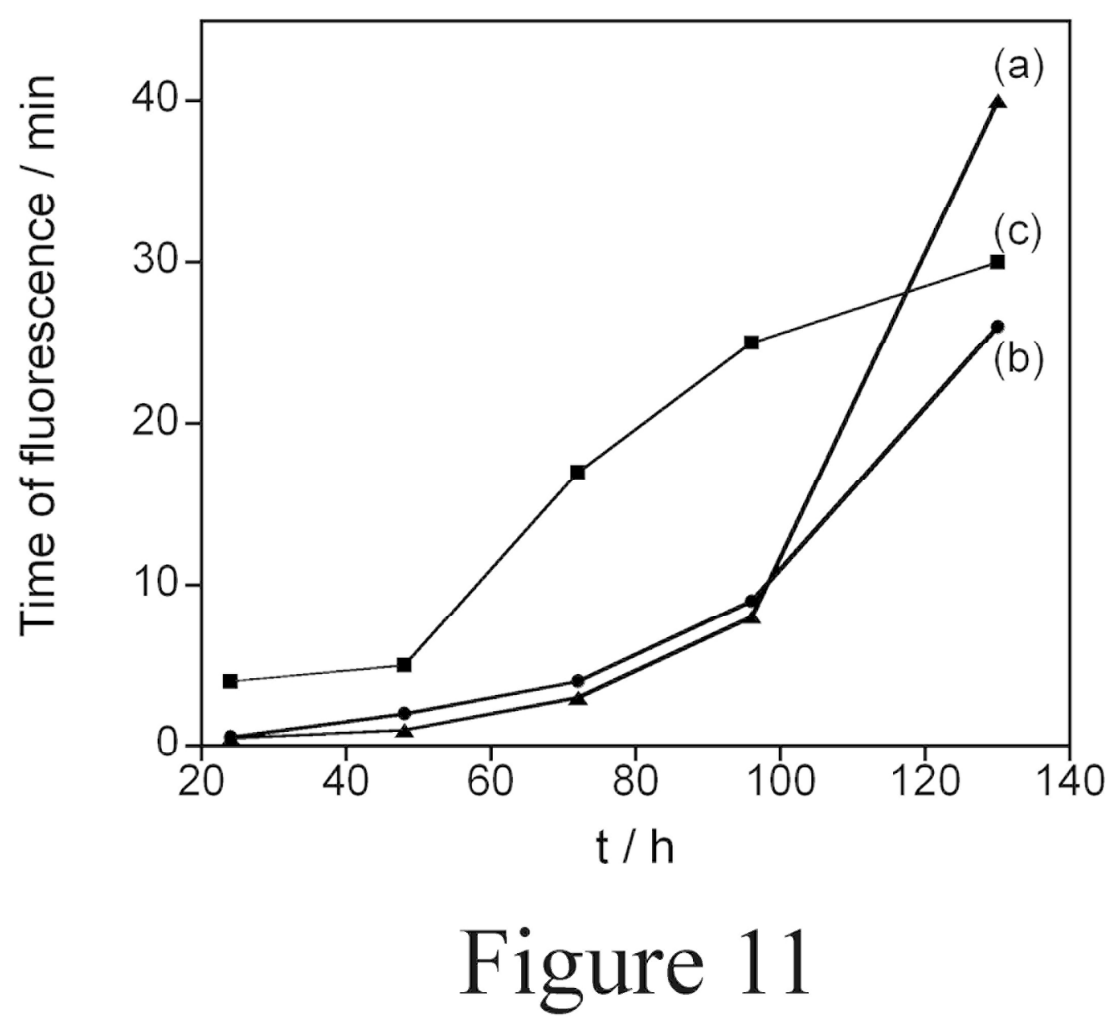




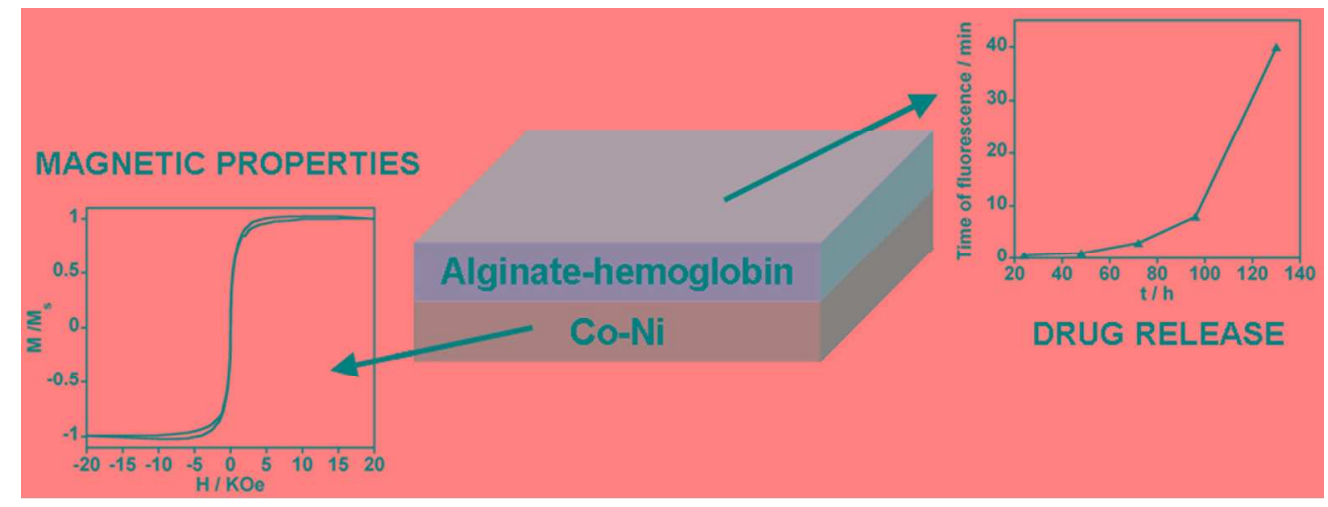

